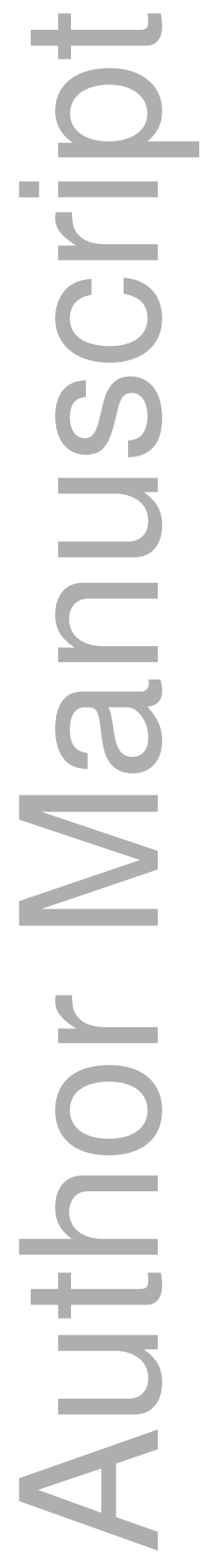

This is the author manuscript accepted for publication and has undergone full peer review but has not been through the copyediting, typesetting, pagination and proofreading process, which may lead to differences between this version and the Version of Record. Please cite this article as doi: $\underline{10.1111 / a j o .13111}$

This article is protected by copyright. All rights reserved 


\section{Accuracy of clinical suspicion of growth restriction at term despite a normal growth ultrasound: A retrospective cohort study}

Brittany GREEN MD, BBMed ${ }^{1}$, Lisa HUI MBBS PhD ${ }^{2}$, Roxanne HASTIE BBiomedSci, PhD ${ }^{1,2}$,

Stephen TONG MBBS, $\mathrm{PhD}^{1,2}$, Fiona C. BROWNFOOT MBBS, $\mathrm{PhD}^{1,2}$

${ }^{1}$ Translational Obstetrics Group, Department of Obstetrics and Gynaecology, University of Melbourne, Mercy Hospital for Women, 163 Studley Road, Heidelberg 3084, Victoria, Australia.

${ }^{2}$ Mercy Perinatal, Mercy Hospital for Women Heidelberg, Victoria, Australia

\section{Corresponding Author}

Dr Fiona Brownfoot

Translational Obstetrics Group, University of Melbourne

Mercy Hospital for Women, 163 Studley Rd., Heidelberg 3084, Victoria, Australia

Email: Fiona.brownfoot@unimelb.edu.au

Phone: $+61384584444 \quad$ Fax : $\quad+61384584380$

Word count: Abstract words 249, Total word count 2341

Short title: clinical suspicion of small for gestational age at term

\section{Authors title and email address}

Dr Brittany GREEN, green.brittanym@gmail.com

Associate Professor Lisa HUI, lisa.hui@unimelb.edu.au

Dr Roxanne HASTIE, hastie.r@unimelb.edu.au

Professor Stephen TONG, stong@unimelb.edu.au

Dr Fiona C.BROWNFOOT, Fiona.brownfoot@unimelb.edu.au 
Acknowledgements: Many thanks to Ms Tanya Fletcher at the Mercy Hospital for Women for assisting us with the patient databases.

\section{Declaration}

Conflict of interest / disclosure statement: The authors report no conflict of interest.

\section{Author contribution}

Brittany Green obtained the data, analysed the data and wrote the manuscript. Fiona Brownfoot, Lisa Hui and Stephen Tong designed the study, assisted with statistical analysis of the data and edited the manuscript. Roxanne Hastie assisted with statistical analysis and edited the manuscript.

Sources of funding:. FB, ST and LH were supported by NHMRC Fellowships (FB \#1142636, ST \#1062418 and LH \#1105603). The funders had no role in study design, data collection, analysis, decision to publish or the preparation of the manuscript.

\section{Ethics approval}

Ethics approval for the project was obtained from the Mercy Hospital for Women Human Research Ethics Committee (approval project number R16/75). As this was a retrospective cohort study, individual patient consent was not required (in accordance with the ethics board).

\section{Edited manuscript to remove identifiers.}

I have been asked to remove the name of the hospital from the methods section of the paper. This should read:

\section{'Material and methods}

We undertook a retrospective study of women having a planned birth at term for SGA despite a normal growth ultrasound at $\geq 35$ weeks' gestation at the Mercy Hospital for Women, a tertiary obstetric hospital in Melbourne, Australia.' 
DR. BRITTANY GREEN (Orcid ID : 0000-0001-5680-6853)

DR. ROXANNE HASTIE (Orcid ID : 0000-0002-4342-1943)

DR. FIONA C BROWNFOOT (Orcid ID : 0000-0002-1439-7016)

Article type : Original Manuscript

Accuracy of clinical suspicion of growth restriction at term despite a normal growth ultrasound: A retrospective cohort study

Brittany GREEN MD, BBMed ${ }^{1}$, Lisa HUI MBBS PhD ${ }^{2}$, Roxanne HASTIE BBiomedSci, $\mathrm{PhD}^{1,2}$, Stephen TONG MBBS, $\mathrm{PhD}^{1,2}$, Fiona C. BROWNFOOT MBBS, $\mathrm{PhD}^{1,2}$

${ }^{1}$ Translational Obstetrics Group, Department of Obstetrics and Gynaecology, University of Melbourne, Mercy Hospital for Women, 163 Studley Road, Heidelberg 3084, Victoria, Australia.

${ }^{2}$ Mercy Perinatal, Mercy Hospital for Women Heidelberg, Victoria, Australia

\section{Corresponding Author}

Dr Fiona Brownfoot

Translational Obstetrics Group, University of Melbourne

Mercy Hospital for Women, 163 Studley Rd., Heidelberg 3084, Victoria, Australia

Email: Fiona.brownfoot@unimelb.edu.au

Phone: $+61384584444 \quad$ Fax : $\quad+61384584380$

Word count: Abstract words 249, Total word count 2341

Short title: clinical suspicion of small for gestational age at term

Authors title and email address and position title

Dr Brittany GREEN, green.brittanym@gmail.com, registrar

Associate Professor Lisa HUI, lisa.hui@unimelb.edu.au, clinician scientist

Dr Roxanne HASTIE, hastie.r@unimelb.edu.au, scientist 
Professor Stephen TONG, stong@unimelb.edu.au, clinician scientist

Dr Fiona C. BROWNFOOT, Fiona.brownfoot@unimelb.edu.au, clinician scientist

Acknowledgements: Many thanks to Ms Tanya Fletcher at the Mercy Hospital for Women for assisting us with the patient databases.

\section{Declaration}

Conflict of interest / disclosure statement: The authors report no conflict of interest.

\section{Author contribution}

Brittany Green obtained the data, analysed the data and wrote the manuscript. Fiona Brownfoot, Lisa Hui and Stephen Tong designed the study, assisted with statistical analysis of the data and edited the manuscript. Roxanne Hastie assisted with statistical analysis and edited the manuscript.

Sources of funding: FB, ST and LH were supported by NHMRC Fellowships (FB \#1142636, ST \#1062418 and LH \#1105603). The funders had no role in study design, data collection, analysis, decision to publish or the preparation of the manuscript.

\section{Ethics approval}

Ethics approval for the project was obtained from the Mercy Hospital for Women Human Research Ethics Committee (approval project number R16/75). As this was a retrospective cohort study, individual patient consent was not required (in accordance with the ethics board).

Word count: Abstract words 248, Total word count 2482

Number of tables: 2, Number of figures: 1

\section{Keywords}


Fetal growth restriction, intra-uterine growth restriction, induction of labour, prenatal ultrasound

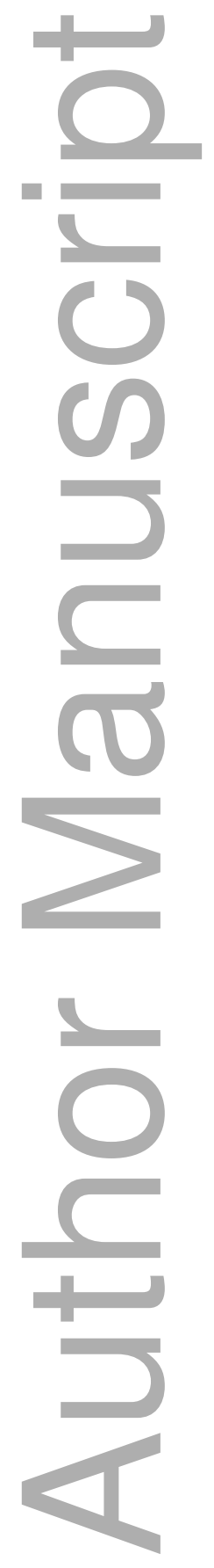


Clinical suspicion of small for gestational age at term

Abstract

Background

Small for gestational age (SGA) is a major determinant of poor perinatal outcome. Detecting SGA at term using ultrasound is challenging and we often plan birth based on clinical assessment.

Aims:

To determine the incidence of SGA infants with birthweight $<10^{\text {th }}$ centile among women undergoing planned birth at term for suspected small for gestational age (SGA) despite a normal estimated fetal weight (EFW) on ultrasound at 35-37 weeks.

\section{Materials and methods}

We performed a retrospective study including all women with a fetal growth ultrasound at $\geq 35$ weeks reporting an $\mathrm{EFW} \geq 10^{\text {th }}$ centile (appropriate for gestational age, AGA) who subsequently had an induction of labour or caesarean birth at $\geq 37$ weeks due to ongoing clinical suspicion of SGA between 2012-2014. The primary outcome was the incidence of SGA newborns using customised centiles.

\section{Results}

There were 532 women that had a planned birth for clinical suspicion of SGA during the study period. Of these, $205(38.5 \%)$ had an AGA fetus on ultrasound $\geq 35$ weeks but were subsequently delivered because of a persisting clinical suspicion of SGA on abdominal assessment. 68\% $(n=139 / 205)$ delivered an SGA infant. Furthermore, almost half of these SGA infants $(47.5 \%)$ had a birthweight $<3^{\text {rd }}$ centile. Neonatal outcomes were worse for the SGA infants, with $15.1 \%(\mathrm{n}=21 / 205)$ requiring special care nursery compared to $1.5 \%$ $(n=1 / 205)$ of those AGA grown at birth.

\section{Conclusions}


A reassuring ultrasound with $\mathrm{EFW} \geq 10^{\text {th }}$ centile in the late third trimester should not override clinical concerns of impaired fetal growth at term.

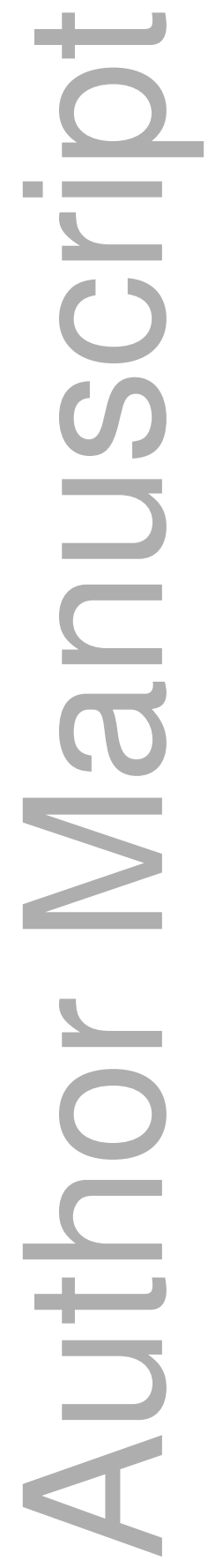


Clinical suspicion of small for gestational age at term

\section{Introduction}

Small for gestation age (SGA) is a major determinant of poor perinatal outcome. Defined as a birth weight of $<10^{\text {th }}$ percentile, it is a surrogate marker for fetal growth restriction. It is associated with fetal distress, seizures, cerebral palsy, behavioural problems, hypoglycaemia and perinatal mortality ${ }^{1-4}$. These adverse outcomes are more pronounced in babies with extremely low birthweight. If women with a growth restricted baby at term are expectantly managed the incidence of extreme SGA doubles, ${ }^{5}$ hence it seems reasonable to undertake a planned birth in these women. Importantly, if women with SGA are identified and managed appropriately (surveillance and timely delivery) there is evidence that the stillbirth rate can be reduced by half 6 , 7 .

Our current methods for identifying the presence of an SGA fetus at term are modest. Women without risk factors for SGA are screened clinically with abdominal palpation and symphysio-fundal height measurements at prenatal clinic appointments ${ }^{3,8}$. If there is clinical concern the fetus may be SGA then an ultrasound is often requested to derive an estimated fetal weight ${ }^{9}$. This approach to screening was examined in Sovio et $\mathrm{al}^{5}$ which demonstrated selective ultrasound only identified $20 \%$ of pregnant women with SGA in the population.

Due to the known inaccuracies of ultrasound at term ${ }^{10}$ coupled with the serious consequences of misdiagnosing $\mathrm{SGA}^{6,7}$ some clinicians still recommend planned birth among women ren

where there is ongoing clinical suspicion of SGA at term gestation, despite a normal growth ultrasound. Surprisingly, whether or not this approach identifies considerably more SGA fetuses' than the expected population incidence of $10 \%$ has not been examined. 
Thus, we set out to determine rates of SGA among women undergoing planned birth for prenatal clinical suspicion of SGA, despite a normal estimated fetal weight (EFW) on a recent ultrasound.

\section{Materials and methods}

We undertook a retrospective study of women having a planned birth at term for SGA despite a normal growth ultrasound at $\geq 35$ weeks' gestation at the Mercy Hospital for Women, a tertiary obstetric hospital in Melbourne, Australia. We included participants who had a planned birth at $\geq 37$ weeks for suspected SGA accompanied by an ultrasound EFW $\geq 10^{\text {th }}$

centile at $\geq 35$ weeks' gestation. The ultrasound scans were performed by sonographers or clinicians trained in ultrasound. Ultrasound scans performed by sonographers or clinicians in training were all reviewed by a senior sonographer, radiologist or clinician with a diploma of diagnostic ultrasound. EFW centiles were calculated using the Australian EFW charts recommended for use in our institution. These charts derive an intrauterine growth curve by utilising a coefficient from the birthweights of Australian infants at 40 weeks $^{11}$ and placing this into a calculator which was previously published by Mikolajczyk and Hadlock ${ }^{12}$ (Figure S1 and Figure S2). Birthweight centiles were derived using the GROW chart customised for the Australian population ${ }^{13}$ and for the height and weight of our participants where it was documented. We did not customise for ethnicity as this can be difficult to determine in our population and there is controversy surrounding whether socioeconomic differences may result in birthweight discrepancies between $\operatorname{races}^{14}$.

We excluded multiple pregnancies, those where SGA was suspected prior to 35 weeks' gestation and those complicated by a fetal congenital anomaly (Figure 1). 


\section{Clinical practice for suspicion of SGA at term}

All pregnant women birthing at our institution have weekly consultations with a midwife or doctor from 36 weeks and symphysiofundal height (SFH) is recorded at each visit to monitor fetal growth. SGA is suspected if there is a static SFH (ie no change on serial weekly measurements) or SFH of $<2 \mathrm{~cm}$ than expected for gestation (based on $\mathrm{SFH} \mathrm{cm}=$ gestational age weeks), or if the uterus is small for gestation as determined by clinical palpation.

If SGA is suspected, women are often referred for a growth ultrasound. It is routine clinical practice in our institution to recommend planned birth before 40 weeks (either via induction of labour or elective caesarean birth) for women with suspected SGA at term. If the ultrasound demonstrates an $\mathrm{EFW} \geq 10^{\text {th }}$ centile, and maternal and fetal well-being are normal, then management is usually expectant. However, if a clinical suspicion of impaired fetal growth persists despite an ultrasound $E F W \geq 10^{\text {th }}$ centile, then planned birth may still be recommended at the clinician's discretion.

\section{Data Collection}

We accessed electronic hospital databases containing all planned births between January 2012 to December 2014. We searched these databases using the pre-specified delivery indication of 'suspected SGA' to identify participants. Routinely collected obstetric and perinatal data including ultrasound reports were retrieved from electronic and paper hospital records.

\section{Outcomes}

This article is protected by copyright. All rights reserved 
The primary outcome was the rate of birthweight $<10^{\text {th }}$ centile as a proportion of women delivered for suspected SGA following a normal growth ultrasound done $\geq 35$ weeks gestation. Birthweight centile was calculated using the GROW calculator customised for the Australian population ${ }^{13}$, 15 . Secondary outcomes included birthweight $<3^{\text {rd }}$ centile, gestation at birth, interval between ultrasound and delivery, the mode of delivery, post-partum haemorrhage, and neonatal admission to the special care nursery or neonatal intensive care.

\section{Statistical analysis}

Statistical analysis was performed using GraphPad Prism 7 (GraphPad Software, La Jolla, CA) with a Student's t-test for continuous variables that approximated a normal distribution and Mann-Whitney U tests for skewed data and a Fisher's exact test for categorical variables. Data were expressed as a median and interquartile range (IQR) or a percentage of total. Statistical significance was defined as a $p$ value $<0.05$.

\section{Ethics}

Ethics approval for the project was obtained from the Mercy Hospital for Women Human Research Ethics Committee (approval project number R16/75). As this was a retrospective cohort study, individual patient consent was not required (in accordance with the ethics board).

\section{Results}

A total of 532 women with singleton pregnancies had a planned birth for suspected SGA at term during the study period. Of these, 265 were delivered on clinical grounds alone (no ultrasound) with $117(44.2 \%)$ being SGA at birth and we excluded these from further analysis. A further 267 had an ultrasound and of these, 62 (23.2\%) were diagnosed with EFW 
$<10^{\text {th }}$ centile. Of this cohort we were able to determine the predictive accuracy of ultrasound. We found that the prevalence of SGA at birth was $68.9 \%$ in participants referred for a growth ultrasound and subsequently birthing for suspected SGA. The sensitivity of ultrasound was low at $24.5 \%$ however specificity was reasonable at $79.5 \%$. The negative predicative value of ultrasound was similarly low at $32.1 \%$ whilst positive predictive value was reasonable at $72.6 \%$. For the purposes of our study we excluded participants that had a planned birth as a result of SGA diagnosed on ultrasound.

Our final cohort thus consisted of 205 women who had an AGA fetus on ultrasound at 35-37 weeks but were induced or had a caesarean section due to ongoing clinical suspicion of growth restriction (Figure 1). Sixty-eight percent $(n=139 / 205)$ of infants born to women in our cohort had birthweights $<10^{\text {th }}$ centile (Table 1$)$. Almost half of these infants $(66 / 139$, 47.5\%) had birthweights below the $3^{\text {rd }}$ centile. Importantly outcomes were worse for babies with SGA: $15.1 \%(n=21 / 139)$ SGA babies required special care nursery compared to $1.5 \%$ $(n=1 / 66)$ of those that were normally grown at birth (Table 2).

The demographic characteristics of the cohort are presented in table 1 . There were no significant differences in maternal age, parity, body mass index, chronic medical disease or a past history of SGA between the women with AGA and SGA infants. Women with SGA infants had their ultrasound earlier in gestation and had lower EFW centile (20\% compared to $30 \%$ ) and EFW (2478g compared to 2678g) compared with women with AGA infants. Ultrasound measures of placental function (umbilical artery resistance and amniotic fluid index) were similar between the groups (Table 1). 
There were no differences in the gestation at delivery of those born SGA median 38.6 (IQR (interquartile range) 38-39.6 weeks) compared to AGA infants median 38.8 weeks (IQR 38 39.9 weeks). The length of gestation from ultrasound to delivery was similar between groups at $2.2(95 \%$ CI $1.9,2.4)$ weeks in those SGA at birth and $2.1(95 \%$ CI $1.7,2.4)$ weeks for those with normal birth weight. Mode of delivery and postpartum complications were also similar between the groups (Table 2).

\section{Discussion}

\section{Main findings}

This study was designed to assess the accuracy of clinical detection of term SGA in the setting of a normal EFW at 35-37 weeks. We found that clinical judgment was correct in more than two thirds of cases. Detecting SGA at term is paramount as it has the highest population attributable risk to stillbirth ${ }^{16}$. Unfortunately, selective ultrasound only detects $20 \%{ }^{3}$ of cases of SGA. Our findings highlight the value of continued physical examination to assess fetal growth and the pitfalls of relying on ultrasound alone for detection of fetal growth restriction at term.

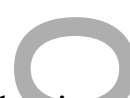

We also investigated the overall detection rate of SGA in our cohort that had an ultrasound for suspected SGA. When we added the numbers of participants with correctly diagnosed SGA on ultrasound to those with SGA detected on clinical exam following a normal growth scan, we found our SGA detection rate was $72 \%(n=193 / 267)$. Together, these findings confirm the enduring value of clinical examination and judgment.

\section{Interpretation}


The mean birthweight centile of the SGA group was very low at $3.88 \%$ indicating a group with substantially more severe in utero compromise than the AGA group. While our study was underpowered to measure differences in serious perinatal outcomes such as stillbirth or neonatal mortality, it is well established that perinatal mortality rises exponentially with lower birthweight centile at $\operatorname{term}^{17}$ and timely identification of SGA fetuses is a key component to preventing stillbirth ${ }^{1-4}, 16$. The SGA group did have significantly higher morbidity demonstrated through higher rates of special care nursery and neonatal intensive care admission.

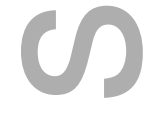

The customised birthweight centile of those born at or above the $10^{\text {th }}$ centile was in the lowest quartile at $22 \%$. Thus, participants with planned birth for suspected SGA on clinical grounds were still generally smaller than average for our population. This suggests that clinical examination may also identify babies with reduced growth velocity, not just small size. It is important to identify this group as they are also at increased risk of stillbirth, with a two-fold increase in perinatal death in babies with a birthweight between the 10-25th centile $^{17}$. Furthermore, a reduced growth velocity is associated with a poor pregnancy outcome ${ }^{3}$.

Several population-based studies determining the accuracy of one third-trimester ultrasound compared to clinical examination without ultrasound to detect SGA at term support the utility of clinical examination and highlight the limitations of ultrasound. Al-Amin et al ${ }^{18}$ reported clinical examination was significantly better at detecting SGA at $54.5 \%$ compared to ultrasound at term at $36.8 \%$. Furthermore, a prospective study comparing clinical assessment to ultrasound in a low-risk pregnancy population found rates of SGA using clinical acumen $(27.9 \%)$ compared with a single third-trimester ultrasound $(24.7 \%)^{19}$. While we did not 
directly compare the overall detection rate of SGA by ultrasound and clinical assessment in our population, our study provides useful information on the positive predictive value of a clinical diagnosis of SGA when it is discordant with recent ultrasound EFW.

It is possible that the two-week time interval between the ultrasound and birth may have influenced the high rates of SGA observed in our cohort. In the Disproportionate Intrauterine Growth Intervention Trial at Term (DIGITAT) ${ }^{5}$, which randomised women with ultrasounddetected fetal growth restriction into planned delivery or expectant management, the group managed expectantly birthed on average 10 days later than those with planned birth and contained twice as many babies $<3^{\text {rd }}$ centile. This lag time between the ultrasound assessment and delivery in the expectant group in DIGITAT is thought to be responsible for the higher proportion of babies in $<3^{\text {rd }}$ centile. It is possible that some of our fetuses that were thought to be AGA at 35-37 weeks were indeed at or above the $10^{\text {th }}$ centile at that time but may have experienced reduced growth velocity in the subsequent two weeks, resulting in a birthweight below the $10^{\text {th }}$ centile.

One of the strengths of our study is the very tight gestational age range of late third trimester ultrasounds in our cohort median 36.4 (IQR 36.0-37.1) weeks. Due to the inaccuracy of EFW at term ${ }^{10}$, fetal growth scans for EFW are not generally performed after 37 weeks in our institution. This means the clinical decision making for the fetuses that were AGA on a 3537-week ultrasound was not confounded by additional EFW estimations.

The retrospective design meant we were unable to formally define SGA and had to rely on the indication nominated by the clinician for the induction of labour or elective caesarean 
section. We were unable to assess other factors that may have contributed to planned birth including the women's preferences and type of practitioner.

We would also note that different methodologies were used to classify EFW and birthweight centiles. The EFW centiles were calculated using an intrauterine growth curve derived from an Australian metropolitan birth cohort ${ }^{11}$ whilst the birthweight centile was calculated using the Australian specific GROW calculator customised for individual maternal height and weight $^{15}$.

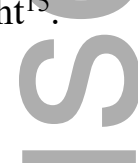

We retained these two methods of assessing fetal growth and birthweight as this was a pragmatic study that assessed clinical management in our institution. Comparison of the parameters used to derive the EFW and birthweight centiles showed general concordance. The mean birthweight used to derive both the intrauterine chart and the Australian population specific GROW chart were similar and we therefore do not think there is much disparity between the two charts. However perhaps slight differences between charts may have contributed to the number of babies born with a birth weight $<3^{\text {rd }}$ centile $(47.5 \%$ of those born $<10^{\text {th }}$ centile). Our study design was pragmatic, and we opted for this as it reflects current clinical practice.

We have found that two thirds of women who had a planned birth due to suspected SGA following a normal growth ultrasound at 35-37 weeks had an SGA infant, with almost one in two of these infants born $<3^{\text {rd }}$ centile. Therefore, an ultrasound EFW $\geq 10^{\text {th }}$ centile in late third trimester should not override clinical concerns of impaired fetal growth at term. Close observation or planned birth for these fetuses should still be considered. 
Clinical suspicion of small for gestational age at term

\section{References}

1 Vashevnik S, Walker S, Permezel M. Stillbirths and neonatal deaths in appropriate, small and large birthweight for gestational age fetuses. Aust N Z J Obstet Gynaecol. 2007; 47: 302-6.

2 MacDonald TM, McCarthy EA, Walker SP. Shining light in dark corners: diagnosis and management of late-onset fetal growth restriction. Aust N Z J Obstet Gynaecol. 2015; 55: 3-10.

3 Sovio U, White IR, Dacey A, Pasupathy D, Smith GCS. Screening for fetal growth restriction with universal third trimester ultrasonography in nulliparous women in the Pregnancy Outcome Prediction (POP) study: a prospective cohort study. Lancet. 2015; 386: 2089-97.

4 Lindqvist PG, Molin J. Does antenatal identification of small-for-gestational age fetuses significantly improve their outcome? Ultrasound Obstet Gynecol. 2005; 25: 258-64.

5 Boers KE, Vijgen SM, Bijlenga D, et al. Induction versus expectant monitoring for intrauterine growth restriction at term: randomised equivalence trial (DIGITAT). BMJ. 2010; 341: c7087.

6 Gardosi J, Madurasinghe V, Williams M, Malik A, Francis A. Maternal and fetal risk factors for stillbirth: population based study. BMJ. 2013; 346: f108.

7 McKenna D, Tharmaratnam S, Mahsud S, Bailie C, Harper A, Dornan J. A randomized trial using ultrasound to identify the high-risk fetus in a low-risk population. Obstetrics and gynecology. 2003; 101: 626-32.

8 American College of O, Gynecologists. ACOG Practice Bulletin No. 101: Ultrasonography in pregnancy. Obstetrics and gynecology. 2009; 113: 451-61.

9 Bricker L, Medley N, Pratt JJ. Routine ultrasound in late pregnancy (after 24 weeks' gestation). Cochrane Database Syst Rev. 2015: CD001451.

10 Ben-Haroush A, Yogev Y, Hod M, Bar J. Predictive value of a single early fetal weight estimate in normal pregnancies. Eur J Obstet Gynecol Reprod Biol. 2007; 130: 18792.

11 Mongelli M, Figueras F, Francis A, Gardosi J. A customised birthweight centile calculator developed for an Australian population. Aust N Z J Obstet Gynaecol. 2007; 47: 12831.

12 Mikolajczyk RT, Zhang J, Betran AP, et al. A global reference for fetal-weight and birthweight percentiles. Lancet. 2011; 377: 1855-61.

13 Gardosi J, Mongelli M, Wilcox M, Chang A. An adjustable fetal weight standard. Ultrasound Obstet Gynecol. 1995; 6: 168-74.

14 Papageorghiou AT, Ohuma EO, Altman DG, et al. International standards for fetal growth based on serial ultrasound measurements: the Fetal Growth Longitudinal Study of the INTERGROWTH-21st Project. Lancet. 2014; 384: 869-79.

15 Health PIfMaC. Customised centile calculator. In: v6.7.6.2(AU), (ed.); 2015.

16 Flenady V, Koopmans L, Middleton P, et al. Major risk factors for stillbirth in highincome countries: a systematic review and meta-analysis. Lancet. 2011; 377: 1331-40.

17 Francis JH, Permezel M, Davey MA. Perinatal mortality by birthweight centile. Aust N Z J Obstet Gynaecol. 2014; 54: 354-9.

18 Al-Amin A, Hingston T, Mayall P, Araujo Junior E, Fabricio Da Silva C, Friedman D. The utility of ultrasound in late pregnancy compared with clinical evaluation in detecting small and large for gestational age fetuses in low-risk pregnancies. J Matern Fetal Neonatal Med. 2015; 28: 1495-9.

19 Bais JM, Eskes M, Pel M, Bonsel GJ, Bleker OP. Effectiveness of detection of intrauterine growth retardation by abdominal palpation as screening test in a low risk

This article is protected by copyright. All rights reserved 
population: an observational study. Eur J Obstet Gynecol Reprod Biol. 2004; 116: 164-9.

\section{Figure Legends}

Figure 1: Flow chart of recruitment.

Figure S1: Intrauterine fetal growth chart

Figure S2: Intrauterine fetal growth table with estimated fetal weight centiles.

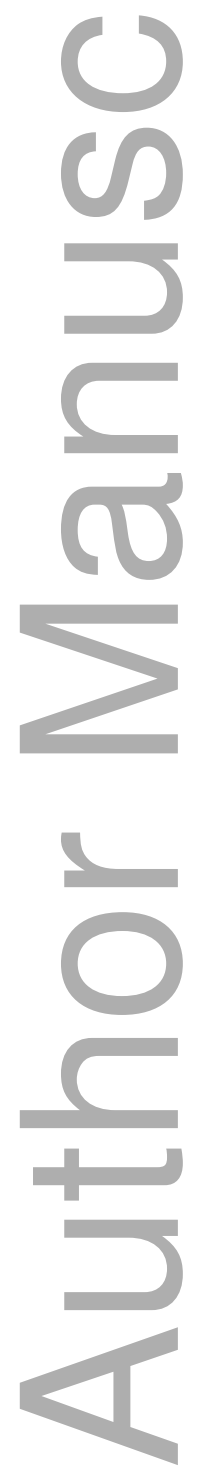




\section{$\underline{\text { Tables }}$}

Table 1 Baseline characteristics of participants delivered for suspicion of SGA in the setting of an ultrasound at $\geq 35$ weeks demonstrating normal growth.

\begin{tabular}{|c|c|c|c|}
\hline r & $\begin{array}{l}\text { Birth weight } \\
<10^{\text {th }} \text { centile } \\
(\mathrm{n}=139)\end{array}$ & $\begin{array}{l}\text { Birth weight } \\
\geq 10^{\text {th }} \text { centile } \\
(\mathrm{n}=66)\end{array}$ & $\mathrm{P}$ value \\
\hline $\begin{array}{l}\text { Maternal Age, years } \\
\text { Median (IQR) }\end{array}$ & $\begin{array}{l}31.0 \\
(28,34)\end{array}$ & $\begin{array}{l}31.0 \\
(27,35)\end{array}$ & 0.67 \\
\hline Nulliparous, n (\%) & $85(61.2 \%)$ & $32(48.5 \%)$ & 0.10 \\
\hline $\begin{array}{l}\text { Body mass index, } \mathrm{kg} / \mathrm{m}^{2} \\
\text { median (IQR) }\end{array}$ & $\begin{array}{l}22 \\
(20,25)\end{array}$ & $\begin{array}{l}22 \\
(20,25)\end{array}$ & 0.7 \\
\hline 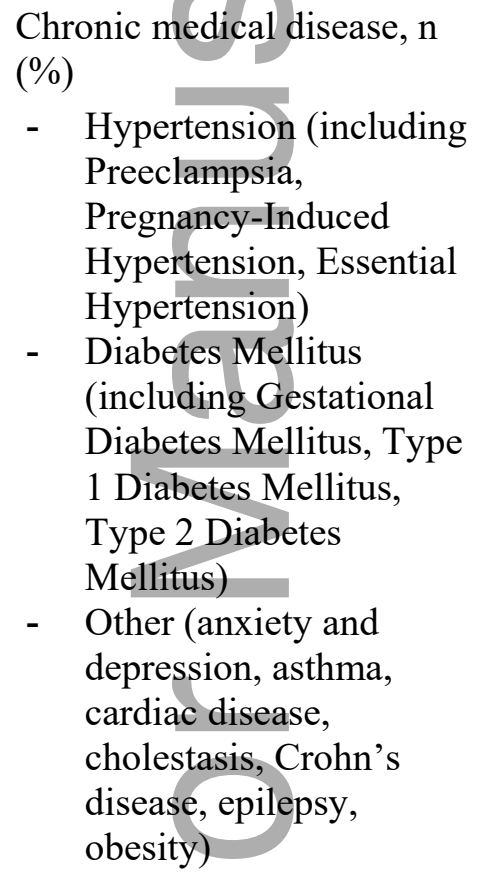 & $\begin{array}{l}6(4.3 \%) \\
13(9.4 \%)\end{array}$ & $7(10.6 \%)$ & 0.8 \\
\hline Past history SGA, n (\%) & $12(8.6 \%)$ & $7(10.6 \%)$ & 0.62 \\
\hline $\begin{array}{l}\text { Gestation ultrasound } \\
\text { performed, median (IQR) }\end{array}$ & $\begin{array}{l}36.4 \\
(36,37.1)\end{array}$ & $\begin{array}{l}36.6 \\
(36,37.6)\end{array}$ & 0.05 \\
\hline $\begin{array}{l}\text { Indication for ultrasound } \\
-\quad \text { Growth and } \\
\text { wellbeing, with nil further } \\
\text { specification } \\
\text { - Clinical suspicion of } \\
\text { SGA } \\
-\quad \text { Diabetes Mellitus } \\
-\quad \text { History of SGA } \\
\text { - No indication } \\
\text { recorded }\end{array}$ & $\begin{array}{l}33(25.6 \%) \\
69(53.5 \%) \\
6(4.7 \%) \\
5(3.9 \%) \\
13(10.1 \%)\end{array}$ & $\begin{array}{l}13(19.7 \%) \\
43(65.2 \%) \\
2(3.0 \%) \\
3(4.5 \%) \\
4(6.1 \%)\end{array}$ & $\begin{array}{l}0.59 \\
0.05 \\
\\
1.00 \\
0.71 \\
0.59\end{array}$ \\
\hline
\end{tabular}




\begin{tabular}{|l|l|l|l|}
\hline $\begin{array}{l}-\quad \text { Other (including } \\
\text { maternal influenza, external } \\
\text { cephalic version, anti Ro } \\
\text { antibodies, reduced fetal } \\
\text { movements) }\end{array}$ & $3(2.3 \%)$ & $1(1.5 \%)$ & 1.0 \\
\hline $\begin{array}{l}\text { Estimated fetal weight, } \\
\text { median (IQR) }\end{array}$ & $\begin{array}{l}2478 \\
(2361,2639)\end{array}$ & $\begin{array}{l}2678 \\
(2514,2856)\end{array}$ & $<0.0001$ \\
\hline $\begin{array}{l}\text { Ultrasound EFW centile, } \\
\text { median (IQR) }\end{array}$ & $\begin{array}{l}20 \\
(15,30)\end{array}$ & $\begin{array}{l}30 \\
(15,48.5)\end{array}$ & $<0.0001$ \\
\hline $\begin{array}{l}\text { Abnormal fetal Dopplers, } \mathrm{n} \\
(\%)\end{array}$ & $8(5.8 \%)$ & $2(3.0 \%)$ & 0.51 \\
\hline $\begin{array}{l}\text { Amniotic Fluid Index }<5 \mathrm{~cm}, \\
\mathrm{n}(\%)\end{array}$ & $3(2.2 \%)$ & $2(3.0 \%)$ & 0.66 \\
\hline Abnormal prenatal CTG & 0 & 0 & \\
\hline
\end{tabular}


Table 2 Outcomes of women being delivered at term for clinical suspicion of SGA despite a normal growth ultrasound.

\begin{tabular}{|c|c|c|c|}
\hline & $\begin{array}{l}\text { Birth weight },<10^{\text {th }} \\
\text { centile } \\
(\mathrm{n}=139)\end{array}$ & $\begin{array}{l}\text { Birth weight } \\
\geq 10^{\text {th }} \text { centile } \\
(\mathrm{n}=66)\end{array}$ & $\mathrm{P}$ value \\
\hline $\mathrm{BW}<3^{\text {rd }}$ centile, $\mathrm{n}(\%)$ & $66(47.5 \%)$ & $0(0 \%)$ & $<0.0001$ \\
\hline $\begin{array}{l}\text { Birth centile GROW, } \\
\text { median (IQR) }\end{array}$ & $\begin{array}{l}3.1 \\
(1.3,6.5)\end{array}$ & $\begin{array}{l}17.8 \\
(13.3,27.3)\end{array}$ & $<0.0001$ \\
\hline $\begin{array}{l}\text { Birth weight }(\mathrm{g}), \text { median } \\
\text { (IQR) }\end{array}$ & $\begin{array}{l}2640 \\
(2500,2850)\end{array}$ & $\begin{array}{l}3105 \\
(2920,3293)\end{array}$ & $<0.0001$ \\
\hline $\begin{array}{l}\text { Secondary Outcomes } \\
\text { Gestation at delivery } \\
\text { (weeks), median (IQR) }\end{array}$ & $\begin{array}{l}38.6 \\
(38,39.6)\end{array}$ & $\begin{array}{l}38.8 \\
(38,39.9)\end{array}$ & 0.21 \\
\hline $\begin{array}{l}\text { Length of gestation } \\
\text { gained since US (weeks), } \\
\text { median (IQR) }\end{array}$ & $\begin{array}{l}2.1 \\
(1.2,3.0)\end{array}$ & $\begin{array}{l}2.0 \\
(0.9,2.9)\end{array}$ & 0.71 \\
\hline $\begin{array}{l}\text { Mode of delivery, n(\%) } \\
\text { NVD } \\
\text { Instrumental } \\
\text { Emergency LUSCS } \\
\text { Elective LUSCS }\end{array}$ & $\begin{array}{l}88(63.3 \%) \\
19(13.7 \%) \\
22(15.8 \%) \\
10(7.2 \%)\end{array}$ & $\begin{array}{l}38(57.6 \%) \\
9(13.6 \%) \\
11(16.7 \%) \\
8(12.1 \%)\end{array}$ & $\begin{array}{l}0.45 \\
0.99 \\
0.99 \\
0.29\end{array}$ \\
\hline $\begin{array}{l}\text { Complications: } \\
\text { Postpartum hemorrhage, } \\
n(\%)\end{array}$ & $6(4.3 \%)$ & $0(0 \%)$ & 0.18 \\
\hline $\begin{array}{l}\text { NEONATAL } \\
\text { Special care nursery and } \\
\text { neonatal intensive care } \\
\text { unit } \mathrm{n}(\%) \\
\text { Special care nursery, } \\
\mathrm{n}(\%) \\
\text { Neonatal intensive care } \\
\text { unit, } \mathrm{n}(\%)\end{array}$ & $\begin{array}{l}21(15.1 \%) \\
18(12.9 \%) \\
3(2.2 \%)\end{array}$ & $\begin{array}{l}0(0 \%) \\
1(1.5 \%)\end{array}$ & $\begin{array}{l}0.0028 \\
0.0009 \\
>0.99\end{array}$ \\
\hline
\end{tabular}

This article is protected by copyright. All rights reserved 


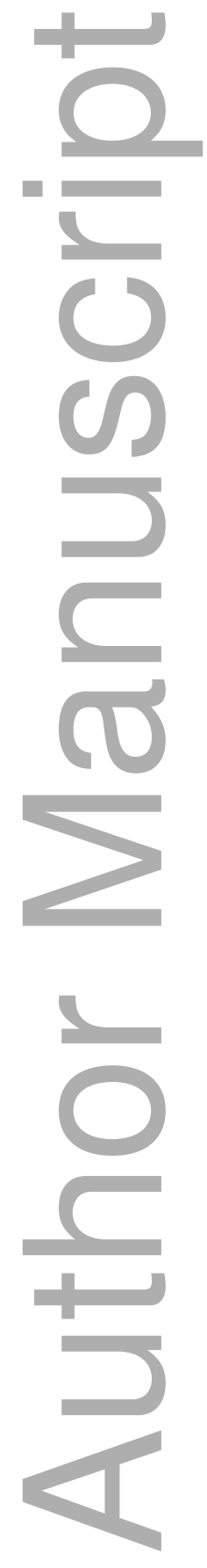

This article is protected by copyright. All rights reserved 


\section{Figure 1}

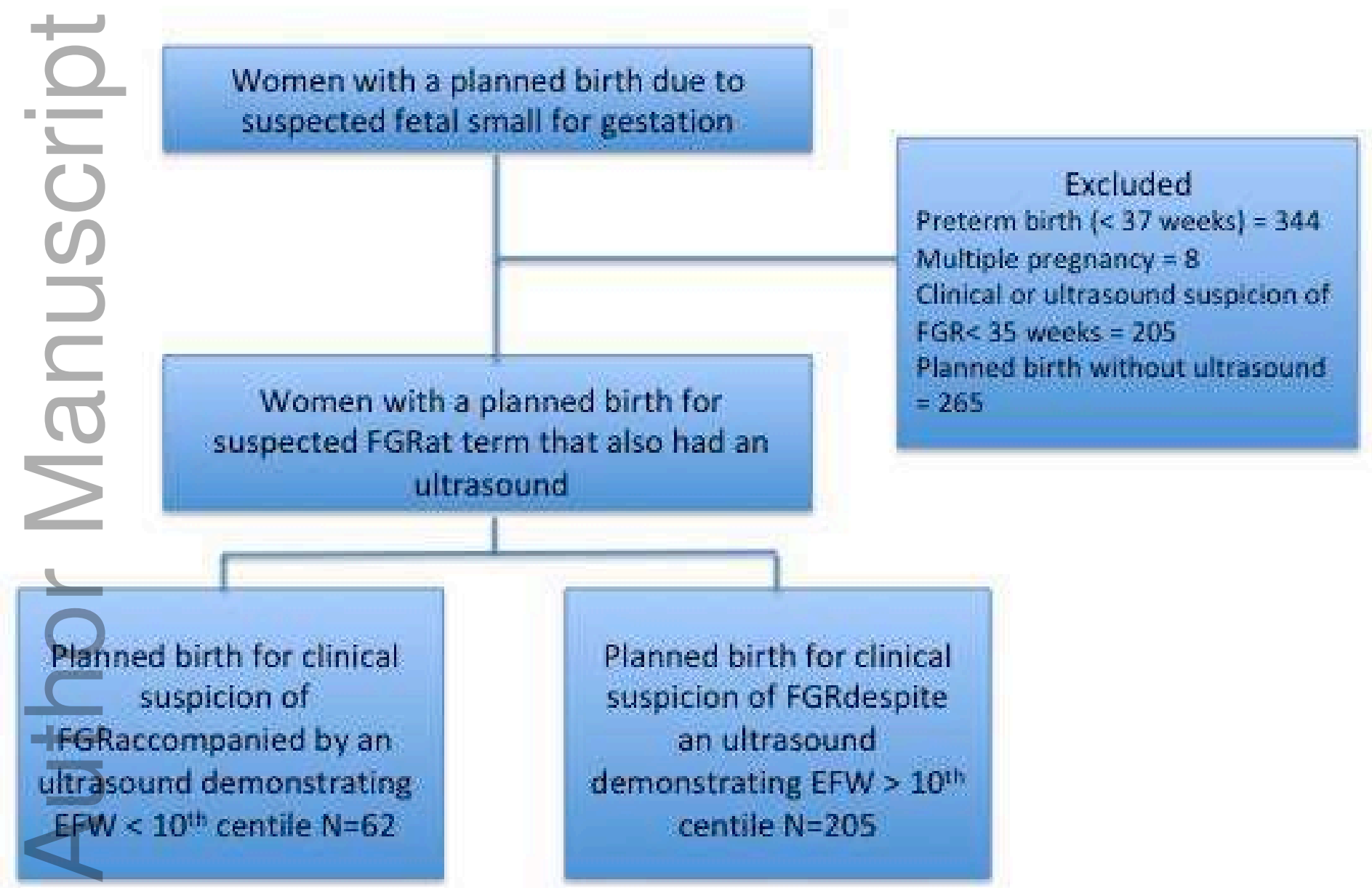

This article is protected by copyright. All rights reserved 


\section{University Library}

\section{- M I I N E R VA \\ A gateway to Melbourne's research publications}

Minerva Access is the Institutional Repository of The University of Melbourne

Author/s:

Green, B;Hui, L;Hastie, R;Tong, S;Brownfoot, FC

Title:

Accuracy of clinical suspicion of growth restriction at term despite a normal growth ultrasound: A retrospective cohort study

Date:

2020-01-09

Citation:

Green, B., Hui, L., Hastie, R., Tong, S. \& Brownfoot, F. C. (2020). Accuracy of clinical suspicion of growth restriction at term despite a normal growth ultrasound: A retrospective cohort study. AUSTRALIAN \& NEW ZEALAND JOURNAL OF OBSTETRICS \&

GYNAECOLOGY, 60 (4), pp.568-573. https://doi.org/10.1111/ajo.13111.

Persistent Link:

http://hdl.handle.net/11343/275249 